\title{
IPSC-derived Natural Killer Cells FT500
}

National Cancer Institute

\section{Source}

National Cancer Institute. iPSC-derived Natural Killer Cells FT 500. NCI Thesaurus. Code C158438.

NCIt Def: A preparation of off-the-shelf, natural killer (NK) cells derived from a clonal master induced pluripotent stem cell (iPSC) line, with potential antineoplastic and immunostimulatory activities. Upon administration, iPSC-derived natural killer cells FT 500 bind to stress-induced ligands on tumor cells, leading to tumor cell lysis and release of tumor neoantigens. Additionally, iPSC-NK cells secrete inflammatory cytokines and chemokines including interferon-gamma (IFN-gamma), tumor necrosis factor-alpha (TNF-alpha), C-C motif chemokines 3, 4, and 22 (CCL3, CCL4, and CCL22), and C-X-C motif chemokine 10 (CXCL10), thereby enhancing $\mathrm{T}$-cell activity and recruitment to the tumor site. 